\title{
PAISAJES HUMANOS LATINOAMERICANOS: CULTURA, TABÚES Y EROTISMO EN “ROMANCE A SAN PEDRO”, UN POEMA SACRO, BURLESCO Y APÓSTATA DE SOR JUANA INÉS DE LA CRUZ ${ }^{1}$
}

\author{
LATIN AMERICAN HUMAN LANDSCAPES: CULTURE, TABOOS AND \\ EROTICISM IN "ROMANCE A SAN PEDRO", A SACRED, BURLESQUE AND \\ APOSTATE POEM BY SOR JUANA INÉS DE LA CRUZ
}

\author{
Marcelo Marinho \\ Universidad Federal de la Integración Latinoamericana, Brasil \\ biografia@gmail.com \\ Rocío Arasy Chamorro Jara \\ Universidad Federal de la Integración Latinoamericana, Brasil \\ rocioarasy@gmail.com \\ Andrés Felipe Buitrago Rodríguez \\ Universidad Federal de la Integración Latinoamericana, Brasil \\ buitragor.andres@gmail.com
}

\begin{abstract}
Resumen:
Sor Juana Inés de la Cruz (México, 1648-1695) es autora de una vasta obra literaria enmarcada por una fuerte ambigüedad y amplia polisemia. En el presente ensayo, se propone la relectura de uno de sus poemas cualificados como sacros por la crítica especializada (Olimón, Sabat de Rivers). Se parte de la constatación de que el texto se estructura sobre un campo lexical en el que se aglutinan innumerables términos que remiten al erotismo y a la sexualidad masculina. Con base en las herramientas interpretativas propias de la hermenéutica, lo que incluye la estilística y aparatos de la filología, proponemos dos versiones parafrásticas al poema, con el fin de explotar la ambigüedad de sentidos que enmarca la obra de la monja anticipadamente feminista, la cual fue condenada por la Inquisición a la renuncia forzada a sus derechos humanos sobre la Grande Poesía.
\end{abstract}

Palabras clave: Sor Juana Inés de la Cruz, Erotismo y literatura, Literatura feminista.

\begin{abstract}
:
Sor Juana Inés de la Cruz (Mexico, 1648-1695) is the author of a large literary work framed within a strong ambiguity and a broad polysemy. This essay is aimed to bring forth a rereading upon one of her poems once qualified as sacred works by some specialized critics (Olimón, Sabat de Rivers). We start from the evidence that the text is structured upon a lexical field in which innumerable terms that refer to eroticism and male sexuality are interwoven. Based on analytical tools related to hermeneutics, which include philologycal apparatus and stylistics tools, we propose two paraphrastic versions for the poem, in order

\footnotetext{
${ }^{1}$ El presente ensayo es resultado de investigaciones subvencionadas por la Fundação Araucária de Apoio ao Desenvolvimento Científico e Tecnológico do Estado do Paraná (Brasil), por medio de becas de investigación concedidas a Rocío Arasy Chamorro Jara y a Andrés Felipe Buitrago Rodríguez.
} 
Dossier. Marcelo Marinho, Rocío Chamorro, Andrés Buitrago. "Paisajes humanos latinoamericanos: cultura tabúes y erotismo en 'Romance a San Pedro', un poema sacro, burlesco y apóstata de Sor Juana Inés de la Cruz"

to exploit the ambiguity of meanings that frames the work of that anticipatedly feminist nun, which was condemned by the Inquisition to a mandatory abdication of her human rights to the Great Poetry.

Key words: Sor Juana Inés de la Cruz, Eroticism and literature, Feminist literature.

Recibido: 03 de mayo de 2021

Aceptado: 03 de junio de 2021

\section{Introducción}

Mucho se ha escrito sobre Sor Juana Inés de la Cruz (México, 1648-1695), según lo asegura Octavio Paz en el prólogo de Las trampas de la fe, en reflejo al espejo caleidoscópico de sus enigmáticas y paradojales personas de monja, mujer y poeta: hay quienes la pintan como religiosa devota, otros como escritora irónica y sarcástica, otros aún como feminista rebelde y combativa. En todos los casos, su genio es unánimemente reverenciado, al paso que sus lectores siguen recorriendo el paisaje socio-cultural latinoamericano que se construye hábilmente en su obra, por medio de un lenguaje entremezclado de lagunas sutiles - silentes y elocuentes a la vez.

En el presente estudio, se indagan los elementos representativos de un cierto paisaje cultural latinoamericano. Por ende, se consideran los paisajes, con el comparatista Claudio Guillén, como espacios imaginarios plasmados por medio de una mirada panóptica, la cual conlleva a "vías de reconocimiento de nuestra situación en el mundo" (Guillén, Paisaje 78). Para los fines específicos de este estudio, el concepto de cultura es tomado de Marvin Harris, que la define como conjunto de "modos socialmente adquiridos de pensar, sentir y actuar de los miembros de una sociedad concreta" (Harris 134). En estos términos, el paisaje cultural se concibe como un conjunto sensible de rasgos y reglas comportamentales humanos (por veces, implícitos) que demarcan los límites de los usos y costumbres individuales o colectivos de un grupo social y, por consiguiente, también determinan los tabúes, es decir, las prácticas humanas sobre las cuales recae el silencio consensual en consecuencia de interdicciones de orden moral o religiosa (Moliner).

Para lograr el presente planteamiento, se adopta una lectura estilística contextualizada del poema sacro "Romance a San Pedro" (de Inundación Castálida, 1689), 
en el cual la crítica especializada (Sabat de Rivers 74) apunta una glosa al recurrente motivo religioso relacionado al evento bíblico de la negación de Jesús por parte de Pedro, su principal apóstol y primer prelado de la Iglesia Católica.

La mirada poética de Sor Juana se plantea, de forma velada y subrepticia, por medio de recursos lingüísticos y estilísticos propios a la estética barroca: ironía, hipérbaton, metonimia, antítesis, metáfora, paradoja, perífrasis, personificación, sinécdoque, elipsis, aliteración, anáfora, homonimia, paronimia, entre otros. Sin embargo, ideas revolucionarias, y a veces apóstatas, están eficazmente disfrazadas bajo imágenes poéticas jocosas y burlescas, temáticas sacras o trucos lingüísticos, como bien lo indica Octavio Paz: "El afán por santificarla, ¿no es una tentativa - quizá no enteramente consciente - por ocultar el verdadero sentido de su vida y de su obra? Si se falsean sus últimos años, se falsea también el significado real de lo que escribió" (Paz 546). Así, el poema se examina bajo una mirada simultáneamente paraguaya, colombiana y brasileña, quizá enmarcada por lagunas y lapsos propios a quienes abordan el poema desde una perspectiva exógena de la cultura mexicana, en términos de tiempo, espacio e inflexiones críticas consensuales y consolidadas.

\section{Obra poética de Sor Juana: breve panorama conceptual y temático}

Como bien lo recuerda Octavio Paz, "Sor Juana habló y escribió el mismo idioma que nosotros, pero durante tres siglos transcurridos desde su muerte no solo han cambiado las formas lingüísticas sino el valor y hasta el significado de las palabras" (Paz 243). Su obra ha resistido al paso de los siglos y sus temas siguen siendo actuales, ya que "si la mudanza de formas y de emociones fuera total, ningún elemento, nacional o supranacional, resistiría al transcurso del tiempo" (Guillén, Entre 31). Por supuesto, sus textos tratan temas que, en el presente siglo XXI, son de una actualidad innegable: patriarcalismo, machismo, opresión social, colonialismo, fe, condición humana y, como veremos adelante, erotismo y sexualidad. Su fortuna crítica se construye sobre prácticas de exégesis que alcanzan aspectos biográficos, psicoanalíticos, teológicos, históricos, literarios y, lo que nos interesa sobremanera, socio-políticos: su obra puede ser leída como la manifestación anticipadamente inaugural del feminismo emancipador que sólo surgiría dos o tres siglos más tarde. 
Dossier. Marcelo Marinho, Rocío Chamorro, Andrés Buitrago. "Paisajes humanos latinoamericanos: cultura tabúes y erotismo en 'Romance a San Pedro', un poema sacro, burlesco y apóstata de Sor Juana Inés de la Cruz"

En Sor Juana Inés de la Cruz o las trampas de la fe, Octavio Paz dirá: "Los lectores terribles son una parte -y una parte determinante- de la obra de Sor Juana. Su obra nos dice algo pero para entender ese algo debemos darnos cuenta de que es un decir rodeado de silencio: lo que no se puede decir" (Paz 16-17). En ese contexto, Manuel Olimón (51-68) enumera y analiza ocho composiciones de Sor Juana que, según él propio, hacen claras loas a San Pedro y plantean un beato "mensaje evangélico" (55), al momento mismo en que el investigador retoma Menéndez y Pelayo para decir que la obra de la monja es también "un curioso documento para la historia de las costumbres coloniales" (55). Desde sus lecturas, ese crítico llega a la conclusión de que la monja es una persona devota, cuya obra sería un fiel retrato de su fe y su espiritualidad: "La palabra adquiere alas cuando se hace poesía y la poesía es siempre dintel de lo divino. Sor Juana nos hace pasar por él con el gozo de quien tiene en la mano más respuestas que preguntas, más esperanza que quebrantos, más luz que tinieblas" (Olimón 52). En contrapunteo, Antonio Alatorre sostiene que muchos críticos suelen juzgar la obra bajo el concepto teológico de la "ciencia infusa", el conjunto de conocimientos otorgados directamente por el Espíritu Santo (Alatorre 333). Georgina Sabat de Rivers subraya la religiosidad de los poemas de Sor Juana y sostiene que el interés de la monja por figuras como la de San Pedro proviene del hecho que el prelado fundador del cristianismo reconoce su "debilidad humana patentizada, más que en ningún otro lugar, en las negaciones de Jesús" (Sabat de Rivers 69).

Octavio Paz afirma que la entrada en convento de Juana Inés es ajena a una vocación religiosa cualquiera, pues proviene de la doble necesidad de evitar la "divina" institución del matrimonio cristiano y de continuar dedicándose a la poesía y al conocimiento, territorio reservado exclusivamente a los varones por entonces ( $\mathrm{Paz} 69$ ). Después del éxito internacional de su Inundación Castálida (1689), la monja, en su famosa "Carta Atenagórica” (1690), se arriesga por más ásperas veredas y abre una crítica de naturaleza teológica a un sermón de autoría (varonil) del Padre Antonio Vieyra (16081697), un jesuita portugués políglota, asentado en Salvador de Bahía (Brasil, en los días de hoy).

Discretamente, de los subterráneos más sombríos del Santo Oficio de la Inquisición, remoliendo su despecho de machos heridos a muerte por la pluma de la monja, los varones salen en su caza a las brujas - o a la bruja que a muchos arrebataba con sus 
hechizos barrocos, la "Décima Musa". Después de su irónica "Respuesta a Sor Filotea de la Cruz" (1691), que Antonio Alatorre califica como texto pionero de la liberación femenina, Sor Juana pasa, en 1693, por un juzgado sub rosa (secreto y sin registros de documentación comprobatoria) y es condenada a renunciar a la escritura y a la lectura. En abril de 1695, cobardemente desplumada y despojada de su razón de vivir, se deja quedar voluntariamente en un convento San Jerónimo azotado por la peste, muriendo prematuramente a los 44 años de edad (en contraste, véase que Vieyra llega bien vivo a sus 89 años...). ¿Sería legítimo hablar aquí de feminicidio? ¿Habrían logrado sus verdugos acceder a las capas palimpsésticas de esa obra, impresa con las debidas autorizaciones y loas varoniles de los cualificadores del Santo Oficio?

El término "palimpsesto", en el ámbito poético, corresponde a las eventuales capas de significación que se podrían leer por debajo de la superficie visible del texto, la capa más inmediatamente accesible a la mirada, como en ciertos antiguos pergaminos que, después de borrados y reutilizados para la escritura, conservan huellas de los textos adrede raspados (Moliner). Es decir, la poesía de Sor Juana es portadora de planes de significación ocultos bajo una capa de texto elusivo, los cuales le permiten plantear ciertas ideas contestatarias, delante de los ojos mismos del Santo Oficio de la Inquisición (Marinho). Por ende, González Boixo señala que, aunque el término "feminismo" sea anacrónico en cuanto a los períodos anteriores al siglo XIX, el concepto resultaría perfectamente adecuado para cualificar los escritos de la monja:

Pretender que Sor Juana encarne un ideario feminista, impensable en su época, conduce a un enfoque erróneo de su personalidad. En cambio, lo que sí es seguro es que sor Juana tuvo una conciencia muy clara de su derecho como mujer al estudio y al desarrollo de su intelectualidad en igualdad con el varón. Sin duda que bien le corresponde a quien luchó por tal fundamental derecho el calificativo de "feminista" (González Boixo 70)

Octavio Paz así sintetiza su lectura simultánea de la obra y de la personalidad de la escritora: "En su interior combatían creencias rivales: el cristianismo y el feminismo, la fe religiosa y el amor a la filosofía. Con frecuencia, y no sin riesgo, triunfaban las segundas" (Paz 498). En los apartados abajo, se toma como hipótesis la idea de que sería 
Dossier. Marcelo Marinho, Rocío Chamorro, Andrés Buitrago. "Paisajes humanos latinoamericanos: cultura tabúes y erotismo en 'Romance a San Pedro', un poema sacro, burlesco y apóstata de Sor Juana Inés de la Cruz"

eventualmente imaginable que ciertas capas palimpsésticas, acerbas y picantes, podrían rebrotar en la superficie misma de inocentes versos sacros o profanos, por efecto de sutiles juegos de campos lexicales y de figuras de estilo propias a la estética barroca.

\section{El Gallo Pedro: ¿romance erótico o burla feminista?}

"Romance a San Pedro" es un poema que Sor Juana desarrolla, en principio, alrededor del primer prelado de la iglesia católica. Un crítico inquieto podría decir que su factura remite, como pretexto, al romancero bíblico de tradición sefardí, es decir, a los "romances construidos alrededor de figuras importantes de la historia religiosa", enfocados en personajes del Antiguo Testamento, tales como Isaac, Moisés, David, Goliat, Absalón, Salomón (Hamos 203) - pero ninguno de entre ellos es cristiano, como lo sería más tarde Pedro, la Piedra de Fundación.

El título mismo del poema presenta un desafío inaugural a sus lectores, pues informa que se trata de un "romance", es decir, composición poética escrita en "octosílabos asonantados" (Chicote 19), con una estructura métrica de origen español que prevé una misma asonancia en las últimas sílabas de los versos pares, mientras los impares no presentan rima ninguna. En resumen, los romances se enmarcan por su condición de poemas "no estróficos, con versos octosílabos de rima asonante regular en los versos pares" (Pedrosa 1074). Así, una lectura más atenta revela que el poema no sería, quizá, propiamente un "romance", ya que no sigue con rigor el requisito relativo a las asonancias al final de versos pares y tampoco trata un tema heroico, amoroso o histórico, como suele serlo, según las convenciones poéticas, o se articula sobre personajes bíblicos del Antiguo Testamento, como se ha constatado. Por ende, ¿qué "romance" podría ahí ocultarse, bajo una escritura elusiva?

La primera capa palimpséstica del poema remite al célebre episodio bíblico en donde el apóstol Pedro niega tres veces a Jesucristo, hasta que un gallo, con su canto, recuerda al apóstol un oráculo que el mismo Cristo había lanzado con anticipación al episodio. Pedro reconoce su culpa y, por ese gesto, alcanza la posición de primer "prelado" del cristianismo, es decir, "aquel que se presenta delante", pues el término viene del latín medieval "praelatus; literalmente 'puesto delante', 'preferido"' (RAE). Así, ese término, que 
hace parte del poema bajo el vocablo "Prelacia" (sic), indica, en principio, la posición de "superior religioso o jerárquico".

En la primera estrofa, "Gallo" se destaca en mayúsculas, en referencia al "Ave" (sic), ser irracional que avisa y reprocha a Pedro por olvidar la razón (la verdad, la justicia o el acierto). De hecho, el "Gallo" se volvió un importante símbolo católico: por orden del Papa Nicolás I (820-867 d.c.), un gallo impera sobre la cumbre de templos católicos, mientras la llamada Misa del Gallo es celebrada en Nochebuena o Navidad.

En esa capa del poema, Sor Juana pone en relieve la compasión humana que es necesaria para quienes aplican la justicia; los ojos "templan" (moderan, entibian, suavizan) la justicia con piedad, una vez que deben juzgar bajo la condición de haber estado en el lugar de los reos o pecadores. La paradoja barroca se ubica en el hecho de que sea necesario haber pecado para llegar a ser Prelado y Juez, para estar en la gracia de Dios y ser el favorito. De ser así, estos versos de Sor Juana tendrían algo en común con el polémico sacerdote ruso Rasputín (1869-1916), que afirmó que "antes de que podamos arrepentirnos, tenemos que pecar", mientras consideraba que era necesario cometer los pecados más atroces, ya que Dios sentiría mayor agrado al perdonar a los grandes pecadores (Cuervo 175). En contrapunto a una versión facsímil del poema, veamos ahora una primera paráfrasis del Romance a San Pedro, versión realizada sin llevar en cuenta rima o métrica:

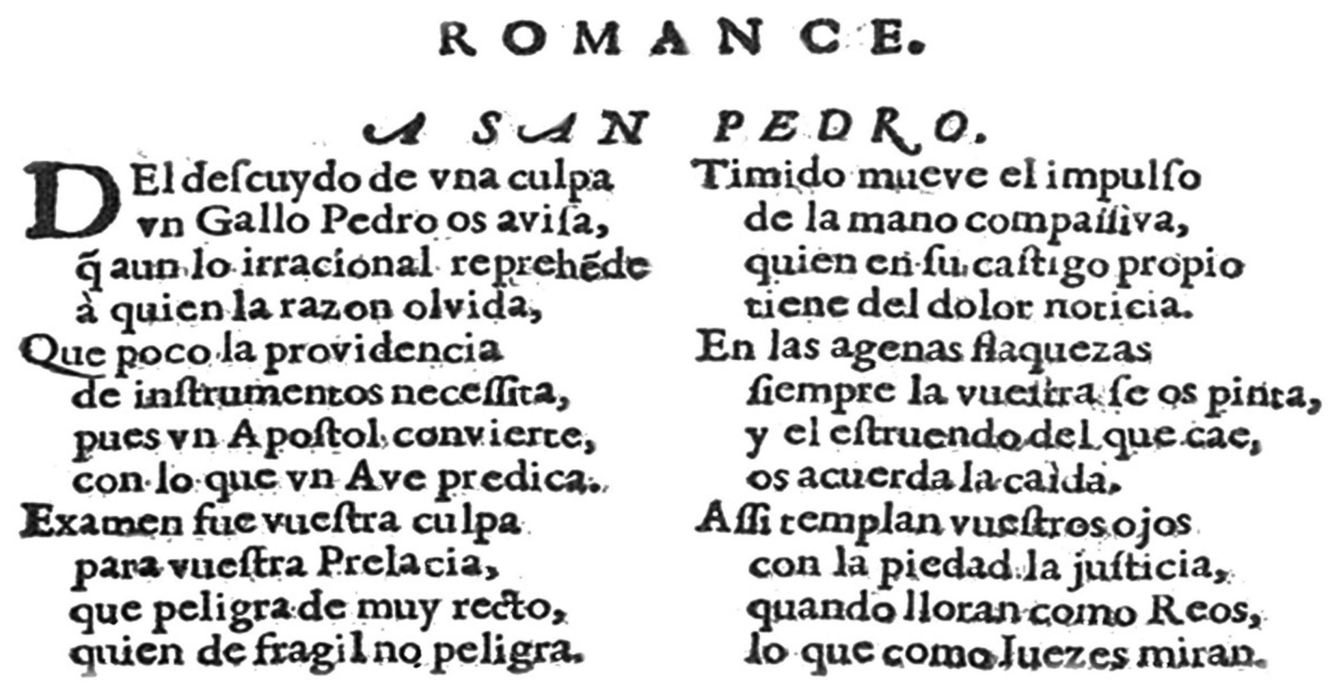

Figura 1. Facsímil del poema “Romance a San Pedro”. Cruz, 1689, p. 209 
Dossier. Marcelo Marinho, Rocío Chamorro, Andrés Buitrago. "Paisajes humanos latinoamericanos: cultura tabúes y erotismo en 'Romance a San Pedro', un poema sacro, burlesco y apóstata de Sor Juana Inés de la Cruz"

\section{Romance a San Pedro}

Pedro, un Gallo te avisa

Del descuido de una culpa

puesto que mismo un irracional

reprende

a quien olvida la razón

Pues que la providencia

poco necesita de instrumentos

una vez que transforma un Apóstol

con lo que un Ave anuncia

$\mathrm{Tu}$ arrepentimiento fue una prueba para tu Prelacia

Pues corre el riesgo de pecar por arrogancia

Aquel que no se arriesga al humilde

repentirse
El que reconoce su propia

culpa

Ya sufre su propio castigo y aplicase con compasión la mano de la punición

Tus flaquezas se reflejan en las flaquezas ajenas y el estruendo del que cae te recuerda tu propia caída

De esta forma tus ojos con piedad ablandan la justicia cuando ven en tu propia culpa los errores que debes juzgar

Como se ve, Sor Juana explota ahí los recursos estilísticos barrocos con maestría: antítesis (racional-irracional; culpa-reprehensión; ave-humano; ave-apóstol; recto-frágil; compasión-castigo; descuido-noticia; piedad-justicia; reo-juez etc.); metonimia ("mano compasiva" es una metonimia de la parte por el todo); personificación ("gallo os avisa", "mano compasiva", “ojos templan” etc.); elipsis (supresión de signos diacríticos, como veremos); quiasmo ("que peligra de muy recto, quien de frágil no peligra" etc.). Además, en sus palimpsestos estructurados en hipérbaton, el poema es pura ironía, como tendremos la oportunidad de analizar. ¿Qué otras capas de lectura, qué nuevos palimpsestos se disimulan bajo esas características poéticas? Desde otra mirada al "Gallo Pedro", el lector podrá darse cuenta que la palabra "gallo" tiene una gran polisemia en el lenguaje cotidiano de los hispanohablantes, y sus significados varían de región a región.

El lector tendrá ahora interés en escudriñar el título del poema ("Romance a San Pedro"), el cual se propondría a anunciar un estilo, género o tipología rigurosa de escritura poética, mientras el poema mucho se aleja de las reglas propias del "romance" hispánico canónico, como ya lo vimos. Desde la edad media, el término "romance" (fr. roman, it. 
romanzo, prov. romans) designa obras escritas en lenguas vernáculas, derivadas del latin, como en El Cantar del Mío Cid, publicado en 1200 d.c. (Prado 40). En el corriente siglo XIII, sale a la luz el célebre "Romanz de la Rose / ou l'art d'Amors est tote enclose" ("Romance de la Rosa, donde todo el arte del Amor se glosa", en nuestra traducción libre del verso). Escrito alrededor de 1230 d.c. por Guillaume de Lorris, y después ampliado por Jean de Meun en el año de 1275 d.c., el libro conoció un gran suceso internacional. Sus versos se escriben en un lenguaje marcadamente sensual, mientras el vocablo "rosa" remite al personaje protagonista, pero sobre todo a la sexualidad femenina. Los demás personajes traen, en gran parte, nombres metonímicos de naturaleza alegórica, y mismo un encuentro erótico tiene inesperado cupo en su estructura, en el curso de una jocosa sátira en contra del abuso de poder y del celibato del clero, razón por la cual volveremos a citar este romance de amor erótico más adelante. Por consiguiente, en este ejercicio hermenéutico sobre este poema mexicano de fines del siglo XVII, es más que legítima la hipótesis de que la palabra "romance" podrá equivaler a "amor" o "historia de amor".

Más tarde, desde el siglo XVIII, el empleo del término "romance" se expande y pasa a tener fuerte relación con la concepción del amor planteado en la literatura por el Romanticismo, en donde, "recorriendo caminos sinuosos en búsqueda de la consolidación amorosa, los personajes, muchas veces vistos como héroes, tropiezan en diversos obstáculos impuestos por la moral de la sociedad burguesa" (Schonarth y Gai 166, traducción nuestra), una idea que será explorada en la lectura del poema vaticinador de la monja mexicana.

Dicha cuestión de la relación metonímica entre "romance" y "amor" se plantea bajo la constatación de una supresión voluntaria de comas en el poema, la cual apunta a un sentido encriptado en el pasaje "un Gallo Pedro os avisa". Si las convenciones y reglas gramaticales hubieran sido observadas, el nombre del apóstol tendría que venir entre comas, pues se trata de un vocativo en posición gramatical de apóstrofe, que cumple una función apelativa: "Pedro, un gallo os avisa". Dada la supresión, el sintagma "Gallo Pedro" asume un posible doble sentido, pues ambos términos podrían intercambiarse en sus funciones de sustantivo y adjetivo: "Pedro" cualifica a "Gallo" (¿gallo pétreo?) o "Gallo" cualifica a "Pedro" (¿Pedro Ave?). La supresión de comas hace que la palabra "gallo" pase 
Dossier. Marcelo Marinho, Rocío Chamorro, Andrés Buitrago. "Paisajes humanos latinoamericanos: cultura tabúes y erotismo en 'Romance a San Pedro', un poema sacro, burlesco y apóstata de Sor Juana Inés de la Cruz"

de sustantivo a adjetivo calificativo. Así: ¿Qué hay de gallo en Pedro para llamarlo de este modo? Por su vez, el antropónimo "Pedro", en su etimología, remite al griego "pétros", o sea, "piedra", condición que recuerda el pasaje bíblico en el que Jesús califica a su apóstol como la piedra angular o fundacional de su iglesia. En ese caso, llegamos a "Gallo-Piedra", “gallo pétreo”. Es decir, ¿el poema haría entonces referencia a una narrativa sobre el amor consumado por un "gallo"?

Por otra parte, "Gallo" también sugiere antiguas asociaciones sígnicas con el dios Príapo (Cirlot 515), un referente de la virilidad masculina por el tamaño privilegiado de su órgano sexual, como se ve representado en varias esculturas, muchas de ellas en piedra. Tal alegoría fálica también se ve en la cultura nativa mesoamericana, con sus monolitos de piedra en forma de pene, que evocan divinidades de los pueblos aborígenes. Vale notar que la influencia cultural autóctona en Sor Juana es constatada por el hecho de que, desde temprana edad, estuvo en contacto con el náhuatl y la cultura de los pueblos originarios de México (Paz; Glantz; Flores). En ese sentido, tengamos en vista un tema mitológico recurrente en la cultura maya, así como en varias otras culturas aborígenes, según la visión del lingüista Ekkehart Malotki: la vagina dentada y el pene de piedra.

Esencialmente, los mitos expresan la creencia en mujeres terribles con dientes en la vagina, las cuales devoran el miembro genital de los hombres que intentan copular con ellas y, según algunas versiones, los matan. Con frecuencia, los héroes logran remover los dientes vaginales utilizando un pene de piedra u otro material duro como bambú, hueso o cuerno de venado, mediante lo cual permiten las relaciones sexuales (Malotki, cit. en Chinchilla 129).

Jorge Oliva, al comentar la naturaleza feminista de tal mito, resalta el hecho de que la castración del varón por "vaginas dentadas" emerge también, más al Sur, en el Gran Chaco, pero sobretodo en la cultura material de los pueblos de México y Perú, bajo la forma de una escultura de piedra que representa el falo, por veces en la talla misma de un ser humano, como si ese órgano pudiera asumir una simbólica apariencia antropomórfica:

Los autores especializados indican en este caso que las mujeres, niñas en realidad, consideran al pene como fuente de poder, también como castigo 
natural al no poseerlo, entonces se comportan como varones para suplir esa carencia, los dientes en la vagina simbolizarían el afán de destruir la fuente de poder del varón. Estas teorías tienen como fuente de inspiración las sociedades europeas del siglo XIX, quizás en eso consiste la imposibilidad de aplicar conceptos de sociedades de predominio masculino a realidades americanas de sociedades matriarcales. (Oliva 6)

Tales elementos mitológicos alrededor de la sexualidad, en el marco de las creencias religiosas de los pueblos autóctonos antes de la conquista y la colonización, se presentan en contrapunteo a los dogmas y tabúes de las religiones abrahámicas en cuanto al cuerpo humano y al erotismo. En este poema, se plantea la posibilidad de emergencia de una alegoría burlesca que mezcla y fusiona, bajo la estética barroca, elementos interculturales en los que señala un asunto de gran actualidad, donde la irracionalidad involucra y apresa a los seres humanos mismos. La lectura aquí prosigue con un ejercicio de paráfrasis interpretativo, con base en la idea de amor erótico, en espera de un eventual hallazgo de significados inéditos.

¿En ese contexto, sería legítimo ver en el "Gallo" una forma de animización para el miembro viril de Pedro, el varón? Esa hipótesis resultaría quizá muy osada para un gran número de lectores de Sor Juana, pero, al examinar el poema, se constata que un largo conjunto de palabras se aglutina en el campo lexical del erotismo: "descuido" (desliz, desacierto, flaqueza en cuanto a la sexualidad), "culpa" (pecado), "irracional” (desatinado, desacertado, erróneo, absurdo, descabellado) “instrumentos" (pene), “Ave” (Pajarito, Gallo, Ganso, Polla, Paloma), "recto" (ano, orificio), "frágil” (débil, humano), “impulso" (atracción, estímulo, instigación, incentivo), “castigo" (corrección, reprensión, enmienda, abstinencia), “dolor" (sufrimiento, martirio, pena, angustia, sacrificio), "flaquezas" (desliz, falta, debilidad, tentación). Se invita al lector a iniciar este recorrido interpretativo, desde aquí.

\section{Pedro, su Gallo, el Pene de Piedra y Onán: tabúes y fricciones interculturales}

En un renovado y novedoso acercamiento al poema "Romance a San Pedro", y con posibilidades de estar frente a una escritura palimpséstica, se propone una paráfrasis interpretativa del texto original que pudiera abrir otras perspectivas de lectura, según este 
Dossier. Marcelo Marinho, Rocío Chamorro, Andrés Buitrago. "Paisajes humanos latinoamericanos: cultura tabúes y erotismo en 'Romance a San Pedro', un poema sacro, burlesco y apóstata de Sor Juana Inés de la Cruz"

título alternativo: "Amor a la moda del Santo de Piedra". La expresión "a la moda de", por veces simplificado en "a la", es una fórmula que proviene del lenguaje culinario, tomado del francés de finales del siglo XVI ("A la"), en expresiones gastronómicas como "bife a lo pobre” (Chile), “tortilla a la española” (Argentina), “conejo a la gitana” (España), "pastor a la gringa” (México), “tacos al pastor” (México), entre muchos otros. También esta forma se encuentra en la cultura artística con expresiones como "amor a la mexicana" (canción) o "teatro a la italiana" (técnica escénica teatral).

Así, la preposición "a” es empleada para referirse a las técnicas o cualidades de algo que se produce. Según la Real Academia de España, "es normal el uso de la preposición ' $a$ ' para introducir complementos verbales que indican el modo de ejecutar la acción" (RAE), por ejemplo, "llamar a gritos, moler a palos, bordar a mano", que si fuera dicho de otra manera en la que se extienda la explicación a detalle, sería algo así como "llamar a la manera gritada", "moler a la manera golpeada con palos" o "bordar al modo manual". Luego, al tomar "Romance a San Pedro" recogiendo el origen etimológico del nombre "Pedro", así como la mencionada posibilidad de la equivalencia metonímica "romance" por "amor", se llega entonces a un "Amor a la manera del Santo de Piedra" o "Amor a la moda del Santo de Piedra", recordando que la palabra moda tiene su origen en el latín modus, la cual refiere a "manera de" (Segura 395). Ahora bien, ¿En qué consiste ese amor a la moda del "santo de piedra"? Véase esta propuesta de paráfrasis a la capa poética alrededor del amor erótico. 


\begin{tabular}{|c|c|}
\hline Romance a San Pedro & Amor a la moda del Santo de Pi \\
\hline $\begin{array}{l}\text { DEl descuydo de vna culpa } \\
\text { un Gallo Pedro os avisa, } \\
\text { q aun lo irracional reprehẽde } \\
\text { à quien la razon olvida, }\end{array}$ & $\begin{array}{l}\text { Un Santo de Piedra te invita } \\
\text { al inimputable de una culpa, } \\
\text { pues el mismo deseo apresa } \\
\text { aquel que olvida la razón, }\end{array}$ \\
\hline $\begin{array}{l}\text { Que poco la providencia } \\
\text { de instrumentos necessita, } \\
\text { Pues vn Apostol convierte, } \\
\text { con lo que vn Ave predica. }\end{array}$ & $\begin{array}{l}\text { Pues el placer pide tan solo } \\
\text { una única herramienta de mano, } \\
\text { y luego convierte un Mensajero, } \\
\text { con lo que un Gallo predica. }\end{array}$ \\
\hline $\begin{array}{l}\text { Examen fue vuestra culpa } \\
\text { para vuestra Prelacia, } \\
\text { que peligra de muy recto, } \\
\text { quien de fragil no peligra. }\end{array}$ & $\begin{array}{l}\text { Tu culpa fue una prueba } \\
\text { al Santo que llevas Delante, } \\
\text { pues peligran de su recto, } \\
\text { los que no de su frágil paloma. }\end{array}$ \\
\hline $\begin{array}{l}\text { Timido mueve el impulso } \\
\text { de la mano compasiva, } \\
\text { quien en su castigo propio } \\
\text { tiene del dolor noticia. }\end{array}$ & $\begin{array}{l}\text { Impulsiona la palma oscilante } \\
\text { de la onana mano enamorada, } \\
\text { quien de puño se estrangula } \\
\text { tanteando sensación de dolor. }\end{array}$ \\
\hline $\begin{array}{l}\text { En las agenas flaquezas } \\
\text { siempre la vuestra se os pinta, } \\
\text { y el estruendo del que cae, } \\
\text { os acuerda la caida. }\end{array}$ & $\begin{array}{l}\text { En los ajenos deslices carnales } \\
\text { siempre tu gansarón se refleja, } \\
\text { y el escándalo del que llora } \\
\text { te recuerda íntimas lágrimas. }\end{array}$ \\
\hline $\begin{array}{l}\text { Assi templan vuestros ojos } \\
\text { con la piedad la justicia, } \\
\text { quando lloran como Reos, } \\
\text { lo que como Juezes miran. }\end{array}$ & $\begin{array}{l}\text { Así vuestros ojos mitigan } \\
\text { el castigo con piedad } \\
\text { cuando Culpables expelen } \\
\text { lágrimas bajo ajeno Juicio. }\end{array}$ \\
\hline
\end{tabular}

El primer verso topicaliza o pone en escena, como mote poético, la cuestión de una “culpa" y su "descuido", es decir, una sencilla "acción reparable o desatención que desdice de aquel que la ejecuta" (RAE). Sin merecer punición o sin más consecuencias adversas, tal acción es la que "avisa" a "un Gallo Pedro", sintagma enmarcado por el artículo indefinido "un”, cuya función es la de generalizar su objeto e indicar que, en este caso, podría remitir a una entidad más que distinta del Santo Prelado, ese mero pretexto para tratar otro asunto. Nótese que "avisar" corresponde también a "llamar a alguien para que preste un servicio" (RAE): ¿el “Gallo Pedro” llama al servicio? Pero: ¿qué servicio? Por la misma vertiente, el 
Dossier. Marcelo Marinho, Rocío Chamorro, Andrés Buitrago. "Paisajes humanos latinoamericanos: cultura tabúes y erotismo en 'Romance a San Pedro', un poema sacro, burlesco y apóstata de Sor Juana Inés de la Cruz"

verbo "descuidar" se contrapone a "pensar profundamente, meditar, reflexionar" (RAE), y su empleo, como se ve bajo el modo imperativo ("Descuida, yo pago"; "Descuida, no hace falta"), podría eventualmente corresponder a una sugestión de despreocupación voluntaria y consciente en cuanto a una acción que no implicaría ninguna forma de culpabilidad, del hecho que el "irracional" puede sobreponerse a la "razón", en el marco de la psique humana.

En el poema, se destacan seis sustantivos grifados en mayúsculas, en el medio mismo de las frases, quizá como alegorías de naturaleza erótica (¿como en el Romance de la Rosa?): “Gallo”, “Apóstol”, “Ave”, "Prelacia”, "Reos” y “Jueces”. “Apóstol” significa "enviado", aquel que camina adelante llevando mensajes, causas o doctrinas; "Prelacia" es la condición de alguien "puesto delante" ("prelado") - ¿el pene en sí propio? ¡Sería por demás de apostasía! En nuestra paráfrasis, proponemos que "mensajero" sea la imagen especular para "Apóstol", sobre todo aquellos "mensajeros" del patriarcalismo, egocentrados en su propio pene, que Sor Juana Inés así denuncia en célebres versos: "hombres necios que acusáis/ a la mujer sin razón,/ sin ver que sois la ocasión/ de lo mismo que culpáis."

Por su vez, en su ambigüedad barroca, "Ave" podría remitir, por metonimia, a rezos, preces y otros rituales sagrados; pero tal vez sea una alusión reiterativa al "Gallo", el cual representaría la parte irracional y más animalesca de los seres humanos, siempre ostentado en la cumbrera de los edificios de la creencia y de las prácticas culturales. Por fin, "Reos" y "Juezes", en términos de sexualidad y erotismo, representarían los dos polos elásticos entre los cuales habita la humanidad, oscilante y sin remisión, desde el advento del "Pecado original", llegado en Abya Yala en los bolsillos mágicos de los conquistadores europeos: todos llevamos, hospedados en los laberintos de nuestro humano ser, un reo y un juez permanentes, construidos con discursos ajenos y por nosotros mismos introyectados $a d$ seculo seculorom, amen.

La "culpa" de la que uno se "descuida" podría ser aquella que tratan Oliveira y Castro, cuando recuerdan que el hecho de "sentir culpa" se aparta de la constatación de "ser culpable", es decir, de la "consciencia de la transgresión de una norma estipulada de antemano" (Oliveira y Castro 253). ¿Cuál es la culpa de la cual "avisa” el Gallo? Si el 
Gallo "avisa", ¿él nos estaría amonestando o más bien convocando al "descuido" y a la acción sin máculas, seguramente reparable, de una "mano compasiva"? ¿Es la culpa una sentencia labrada por el Otro, sea él individual o colectivo?

Véanse ahora otras posibilidades de sentido para el antropónimo "Pedro". Como se sabe, es demasiado común, en múltiples culturas, que el pene reciba nombres masculinos; de Peter (Pedro) a Fabrizio, de Julio Martinez a Don Juan, de Braulio a Zezinho. En un estudio sobre género, cultura e imaginarios varoniles del pene, la lingüista Deborah Cameron subraya esa personificación del miembro masculino, como si fuera una carga, divina e irrevocable, portar un miembro autónomo que siempre le antecede a su involuntario portador:

En Inglaterra, existe un popular personaje de cómic llamado "Wicked Willie" (willie 'penis' es común en el inglés británico), quien es, de hecho, un pene. Éste apareció primeramente en un libro titulado Man's Best Friend. El concepto subyacente es que los hombres secretamente consideran su pene como un individuo por sí mismo y uno al cual están profundamente apegados. Aunque el cómic es una broma, probablemente resuena para una experiencia largamente reconocida y culturalmente construida del pene como un incontrolable Otro, con una vida propia. (Cameron 370, traducción nuestra.)

Entre los apodos de naturaleza animal, es posible destacar nombres como "nutria", “cogote de ganso", "cogote de jirafa" o "culebra". El universo de las aves también se presenta, burlesco, en la jerga popular: "polla”, "pavo”, “paloma”, "ganso”, “pajarito”, “calopsita”, "gansarón”, "gallito inglés", entre otros. Entre tales nombres, "gallo" se torna una referencia fálica debido a sus cualidades animales (dudosas, por supuesto) de "macho", por lo que "se dice orgullosamente que la verga es un gallo" (Gortati 109). Es inmensa la lista de apodos que, en su mayoría, están excluidos de los diccionarios elaborados por filólogos enmarcados por elevada preocupación con la moral y las buenas costumbres.

En tal contexto, aquella "mano compasiva" no sabría ser ajena a lo que toca, es una mano que interactúa con el mismo cuerpo al que pertenece, para aplicar aquel "castigo propio" o "autocastigo" - es una mano que "siente junto" (“con-pasión"). Cabe recordar que el vocabulario del autoerotismo (masculino) incluye verbos como "estrangular", 
Dossier. Marcelo Marinho, Rocío Chamorro, Andrés Buitrago. "Paisajes humanos latinoamericanos: cultura tabúes y erotismo en 'Romance a San Pedro', un poema sacro, burlesco y apóstata de Sor Juana Inés de la Cruz"

“ahorcar al muchacho", “apuñalar”, "jalar la tripa”, "sacar punta al lápiz”, "clavar una paja", "hacer justicia por propia mano", expresiones cómicas que intentan deshacer los nudos estrechos del castigo psíquico y sufrimiento moral inherentes o resultantes del tabú. Hay que notar, en la última estrofa, una mención a "ojos que lloran", la cual se podría concebir como alusión directa al sufrimiento masculino que se ve en uno de los nombres populares y metonímicos del pene - "el que llora".

¿Sería lícito buscar otros chistes placenteros en la palabra "mano", una vez que la estética barroca pone gran énfasis en los juegos verbales espacio-visuales, como los acrósticos, palíndromos o caligramas? Adrede, el poema parece hacer una discreta referencia anagramática a Onán (onam-mano), personaje bíblico que, en un acto de desobediencia a un dogma divino, habría echado su semen por sobre el suelo. Siglos más tarde, Onán prestaría su nombre a aquel acto de autosatisfacción condenado por la moral y las buenas costumbres, uno de los más arraigados tabúes de todos los tiempos: el onanismo. Entonces, en la paráfrasis, se toma la libertad de recurrir a una licencia poética para llegar a la expresión "onana mano enamorada", cuya aliteración rítmica podría mimetizar el acto mismo de la práctica corporal condenada en aquella figura bíblica. Sí, lector, claro está, la “mano enamorada" es aquella que se impulsa "con pasión", la mano "con-pasiva".

Así, las "ajenas flaquezas" corresponderían a los impulsos eróticos condenados como irracionales, cuando sucumben bajo el juzgado de terceros, mientras la expresión elíptica "la vuestra" podría doblemente referirse a la flaqueza misma como también a su móvil, "la vuestra verga" (por elipsis). En ese contexto, la "providencia" se concibe como sinónimo para "felicidad", "gozo", "plenitud”, "satisfacción”. Además, la palabra "instrumento" es otra forma diccionarizada de designar al "pene", órgano de un cuerpo que aquí se tomaría como instrumento para la satisfacción del placer al que invita ("avisa") el "Ave" (gallo, paloma, gansarón) que "predica”, es decir, que "se pronuncia adelante" (predica, dice-ante). Cabe notar que es precisamente ese desliz (¿manual?) que conduce al "Gallo" a la "Prelacia", término que podría ser leído como "pre-laxia", es decir, laxitud, laxidad, la condición misma del "gallo" pre-laxo (medio flojo, mole, flácido, abatido), en otro posible juego verbal burlesco y apóstata. 
Ahora podríamos intentar una lectura para estos versos enmarcados por un guapo quiasmo: "que peligra de muy recto,/ quien de frágil no peligra". Las "ajenas flaquezas", las debilidades de la carne, según el poema, serían implacables con todos los varones: los que no corren el riesgo de sucumbir al erotismo de su frágil órgano "prelado" (anterior), tendrán que enfrentarse al deseo erótico que se manifiesta en otros antros, órganos o partes de su cuerpo, en el presente caso, su "recto".

Aquí se podría retomar y glosar a Sabat de Rivers en su clarividente observación sobre el rol privilegiado del Apóstol Pedro en la poesía de Sor Juana, en función del hecho de que el primer Prelado del cristianismo tenga reconocido su "debilidad humana patentizada" (Sabat de Rivers 69), alcanzando por ahí el rescate de su culpa. Desde ese punto de vista, y como se lee en "Romance a San Pedro", la escritora desarrolla la idea de que el impulso erótico se hospeda en todos los seres humanos, o casi todos, mientras las rigurosas reglas patriarcales de las religiones monoteístas insisten en condenar el goce de la "providencia", el cual se termina por desplazar sobre las prácticas pretensamente escusas y ciertamente solitarias del onanismo.

El poema "avisa" (invita, llama, convoca) a mirar con ojos de "Reos" una práctica condenada bajo la mirada de "Jueces" hipócritas - también ellos sometidos al yugo irracional del "Gallo" que llevan por delante, su "Prelacia". Es como si una misma condición que revela la debilidad humana pudiera, por medio del "descuido" (tolerancia, condescendencia o indulgencia), revelar a los animales racionales, que somos todos, algo que nos humaniza, trasciende, sacraliza - es decir, la sexualidad misma, sana y natural, que fuera sacada con violencia del paisaje cultural de Abya Yala tras la llegada de los colonizadores, momento en el que nos descubrimos desnudos y pecadores sin remisión...

\section{Consideraciones finales}

Muy por debajo de la capa poética "sacra" del "romance a San Pedro", sobresale el deseo erótico que apresa a la gran mayoría de seres humanos, los cuales se encuentran a la vez en los papeles de "Juezes" y "Reos", sobre todo cuando se entregan a prácticas eróticas enmarcadas por los tabúes, tales como el onanismo. En contrapunteo, la figura del Gallo Pedro (Gallo Pétreo, Ave de Piedra, Pene de Piedra), a modo de santo y mensajero, invita a 
Dossier. Marcelo Marinho, Rocío Chamorro, Andrés Buitrago. "Paisajes humanos latinoamericanos: cultura tabúes y erotismo en 'Romance a San Pedro', un poema sacro, burlesco y apóstata de Sor Juana Inés de la Cruz"

"descuidarse" de un hecho que en sí mismo no estaría bajo una condición pecaminosa cualquiera, pues el erotismo hace parte la condición humana misma. El poema es intensamente feminista y decolonial cuando trae a la escena un tema tabú mezclado a figuras de la mitología autóctona: el "pene de piedra" es una invención de los varones para enfrentamiento simbólico de la energía femenina, irresistible e inevitable, simbolizada por la "vagina dentada". En términos cristianos, tendríamos ahí quizá la idea de que el pecado original, entre los varones, deriva del hecho mismo de portar un pene delante de sí, cargado de prelacia patriarcal.

Además, al sacar de creencias autóctonas una imagen para recordar a sus lectores la sexualidad abolida y el poder arrebatado a las mujeres por la colonización, Sor Juana pone en cuestionamiento no sólo las rigurosas reglas impuestas por la Iglesia Católica, sino el lugar mismo que las religiones europeas ocupan en el territorio de Abya Yala, ideas que, en plena Inquisición, la podrían haber condenado a las más duras penas, incluso la capital.

Es necesario reiterar que la lectura aquí propuesta permanece como una hipótesis, la cual parece converger con la misteriosa renuncia de Sor Juana a la poesía y su muerte subsecuente, quizá voluntaria, en el convento de Santa Paula. Octavio Paz apuntó esa dirección al decir que, en el juzgado sub rosa sufrido por la monja, "deben haber salido a relucir los poemas eróticos, los morales, los jocosos, las comedias y su obra entera" (Paz 537). ¿Sería lícito considerar su retiro y su muerte como una posible consecuencia de tener sus poemas jocosamente feministas descubiertos? ¿Cuántos otros existen, cuántos son los palimpsestos escondidos magistralmente por esta genial escritora? Es necesario considerar la posibilidad de que, tras la publicación de estas denuncias feministas disfrazadas bajo inocentes poemas sacros, algún lector pudiera haber interpretado el poema en sus capas contestatarias y, por veces, apóstatas.

Octavio Paz, muy acertadamente, sostiene que "la vida y la obra de Juana Inés pueden condensarse en esta frase: el conocimiento es una transgresión cometida por un héroe que luego será castigado. Este castigo es, paradójicamente, según se verá, su gloria" (Paz 122). Así, Sor Juana se plantea como heroína de su propia historia, enfrentando la misoginia y los dogmas que la Iglesia Católica imponía sobre toda la población de las colonias, bajo el yugo del Santo Oficio de la Inquisición. Su gloria se ve en la pervivencia 
de su obra literaria, donde logra plasmar incluso lo más indecible y lo más innominable de los paisajes humanos latino-americanos de entonces y de ahora, y sigue diciéndolo, a la hora misma en que el lector llega al punto final del presente artículo.

\section{REFERENCIAS}

“A La". Etymology Dictionary Online. 2021. www.etymonline.com/word/a\%20la Consultado el 6 de julio de 2020.

Alatorre, Antonio. "Sor Juana y los hombres". Debate Feminista, núm. 9, 1994, pp. 329348. www.jstor.org/stable/42624233?seq=1. Consultado el 3 de junio de 2021

"Apostol". Biblioteca en línea Watchtower. 2020. https://wol.jw.org/es/wol/d/r4/lps/1200000310 Consultado el 3 de junio de 2021.

Cameron, Déborah. "Naming of the parts: Gender, culture and terms for the penis among American College Students". American Speech, núm. 4, 1992, pp. 367-382. https://doi.org/10.2307/455846. Consultado el 1 de junio de 2021.

Chicote, Gloria. "El Romancero en la Edad Media: discurso tradicional y literatura culta". Medievalia. núm. 50, 2018, pp. 13-22. https://revistasfilologicas.unam.mx/medievalia/index.php/mv/article/view/346/398. Consultado el 3 de junio de 2021.

Chinchilla Mazariegos, Oswaldo. "La Vagina Dentada: Una Interpretación de la Estela 25 de Izapa y las Guacamayas del Juego de Pelota de Copán". Estudios de Cultura Maya. núm. 1, 2010, pp. 117-144. http://dx.doi.org/10.19130/iifl.ecm.2010.36.7. Consultado el 3 de junio de 2021.

Cirlot, Juan Eduardo. Diccionario de símbolos. Siruela, 2019.

Cruz, Juana Inés de la. Inundación Castálida. Juan García Infanzón, 1689. Biblioteca Complutense. alfama.sim.ucm.es/dioscorides/consulta_libro.asp?ref=B19009355\& idioma $=0$. Consultado el 15 de febrero de 2021 .

Cuervo, Benedicto Álvarez. "Rasputín en la Corte del Zar Nicolás II". La Razón Histórica. Revista hispanoamericana de historia de las ideas politicas y sociales. núm. 30, 2015, pp. 173-201. https://www.revistalarazonhistorica.com/30-11/ Consultado el 3 de junio de 2021.

Ferrater, José Mora. Diccionario de Filosofía. Sudamericana, 1970.

Flores, Enrique. "Sor Juana y los indios: loas y tocotines". Literatura Mexicana. núm 2, 2007, pp. 39-77. http://dx.doi.org/10.19130/iifl.litmex.18.2.2007.566. Consultado el 3 de junio de 2021.

Glantz, Margo. Sor Juana Inés de la Cruz: ¿Hagiografía o autobiografía? Biblioteca Virtual Miguel de Cervantes. 2005. http://www.cervantesvirtual.com/nd/ark:/ 59851/bmc1r729. Consultado el 3 de junio 2021.

González Boixo, José Carlos. "Feminismo e intelectualidad en Sor Juana". Cuadernos Hispanoamericanos. Los Complementarios, núm. 16, 1995, pp. 69-81. http://www.cervantesvirtual.com/nd/ark:/59851/bmctx5c9. Consultado el 3 de junio de 2021.

Gortati, Elí de. Silabario de palabrejas. Plaza \& Janes, 1988. 
Dossier. Marcelo Marinho, Rocío Chamorro, Andrés Buitrago. "Paisajes humanos latinoamericanos: cultura tabúes y erotismo en 'Romance a San Pedro', un poema sacro, burlesco y apóstata de Sor Juana Inés de la Cruz"

Guillén, Claudio. Entre lo uno y lo diverso. Crítica, 1985.

---. "Paisaje y Literatura, o los fantasmas de la otredad". Actas del X Congreso de la Asociación Internacional de Hispanistas. pp. 77-98, 1989. http://www.cervantesvirtual.com/nd/ark:/59851/bmc3j5d5. Consultado el 31 Mayo 2021.

Hamos, Andrea Warren. "Romancero y Tradición: Los Romances Bíblicos Entre Los Sefardíes." Hispanic Review, vol. 61, núm. 2, 1993, pp. 201-212. www.jstor.org/stable/473966. Consultado el 31 Mayo 2021.

Harris, Marvin. Introducción a la antropología general. Alianza, 1984.

Marinho, Marcelo. Sor Juana Inés de la Cruz (Mexico, 1651-1695) and Gregório de Matos Guerra (Brazil, c.1636-1695): the sarcastic machinery of baroque Irony. Comparative Literature as a Transcultural Discipline, edición de Eduardo de Faria Coutinho. Annablume, 2018, p. 119-152.

---. Sor Juana Inés de la Cruz et la condition féminine en Amérique latine: représentations poétiques de la douleur d'être femme au XVIIe Siècle. L'écriture de la douleur en Amérique latine, edición de Cécile Quintana. Crila Archivos-Université de Poitiers, 2017, p. 219-239.

Moliner, María. Diccionario de uso del español [Versión electrónica]. Gredos, 2001.

Olimón, Manuel. "Luces de la Nueva España: Obra Poética dedicada a San Pedro de Sor Juana Inés de la Cruz". Estudios. núm. 11, 1987, pp. 51-68. http://dx.doi.org/10.5347/01856383.0011.000170171. Consultado el 3 de junio de 2021.

Oliva, Jorge. La mujer y el mito. Biblioteca Virtual Miguel de Cervantes. 2007. www.cervantesvirtual.com/nd/ark:/59851/bmc4t708. Consultado el 5 de octubre de 2020.

Oliveira, Adriano y Eduardo Castro. "Entre Deus, a culpa e o pecado". Psico. núm 2, 2009. pp. 253-259. https://revistaseletronicas.pucrs.br/ojs/index.php/revistapsico/article/ view/1499. Consultado el 3 de junio de 2021.

Prado, Elsa Liliana. Romances viejos do romancero español: análise e tradução. 2016. Universidade Federal de Minas Gerais, Tesis de Maestría (Literatura). https://repositorio.ufmg.br/handle/1843/ECAP-A7DGGC. Consultado el 28 de enero de 2021.

Paz, Octavio. Sor Juana Inés de la Cruz o las trampas de la Fe. Fondo de Cultura Económica, 1994.

Pedrosa, José Manuel. Diccionario filológico de literatura medieval española. Castalia, 2002.

RAE. Real Academia Española. [Versión en línea] 2020. https://dle.rae.es/. Consultado el 3 de junio de 2021.

Sabat de Rivers, Geogina. "Poesía Religiosa de Sor Juana: San Pedro Apóstol". Calíope: Journal of the Society for Renaissance and Baroque Hispanic Poetry. núm. 2, 1999, pp. 69-81. www.jstor.org/stable/44799305\#?seq=1. Consultado el 3 de junio de 2021.

Schonarth, Graciela y Eunice Gai. "Abordagens do amor romântico: aspectos históricos, sociais e literários". Literatura e Autoritarismo. núm. 14, 2015, pp. 164-172. https://doi.org/10.5902/1679849X18522. Consultado el 3 de junio de 2021. 
Segura, Munguía Santiago. Lexicón (incompleto) etimológico y semántico del Latín y de las voces actuales que proceden de raices latinas o griegas. Universidad de Deusto, 2014. 